\title{
Meaning-making and Lexicogrammatical Accuracy Relationships on Multilingual Engineering Teams
}

\author{
Penny Kinnear \\ University of Toronto, Faculty of Engineering and Applied Science, Engineering Communication Program \\ penny.kinnear@utoronto.ca
}

\begin{abstract}
The present reliance on lexicogrammatical accuracy seems to be an impoverished construct on which to assess students' understanding and students' ability to productively interact and use engineering concepts in team settings. I propose supplementing accuracy with the concepts of agility and efficacy because meaning-making seems to be more critical to a student's ability to successfully engage in the complex process of communication than accuracy alone. However, before these can be assessed it is necessary to determine what meaning-making, agility and efficacy look like in practice. This study examines emergent meaning-making practices of video-recorded team meetings in two first-year engineering design courses. Analysis revealed that lexicogrammatical accuracy did not reflect a team's or individual's ability to communicate-to make meaning.
\end{abstract}

Keywords: Lexicogrammatical accuracy, multilingual students, meaning-making, assessment, agility, efficacy, communication skills

\section{INTRODUCTION}

Communication skills comprise one set of the Graduate Outcomes mandated by ABET [1]. Teaching communication skills to engineers and then assessing them is neither straightforward nor easy. The tasks are further complicated by the range of English language proficiencies among our current engineering students. Within our institution the majority of incoming students in 2014-2015 were required to submit English Language Proficiency measures with their applications. A discussion of the changes in university student demographics is outside the scope of this paper, however, it was the challenge of dealing with some of the results of those changes that prompted my current research into assessment and support of professional language development.

Current practices in classroom assessment and language support assume a straightforward relationship between accuracy and meaning and meaning-making: the more accurate a text (oral or written) the more meaning. This assumption begs several questions around the development of discipline specific language, Second Language Acquisition (SLA) and the peculiar space in which advanced language learners find themselves within our institutions. The language space that many, if not the majority of our students inhabit is complex. All students accepted into our engineering program have met the English Language Proficiency requirements for admission. However, research has shown that the test scores are not the best measure of the skills required to successfully participate in a university program. Brooks and Swain have identified potential weak links in the argument that TOEFL scores accurately predict in-class performance [2]. A study conducted at Purdue University found unreliable relationships between aggregated TOEFL scores and GPA, suggesting that a careful consideration of subsection scores may be an important consideration [3]. Thus, many of our students find themselves in an odd place, officially proficient but constantly made aware of their 'deficits' either through assessments, the response of other students, or their own struggles with lectures, texts and assignments. This space demands that students use the language and not study it. Their motivation is no longer assessment of their knowledge of the language but the ability to communicate with the language (communicate here includes making meaning from text and in interactions with others). Current thinking in Usage-Based approaches [4] and dynamic assessment $[5,6]$ assert that people develop their linguistic resources in interactions with others, an assertion commensurate with a sociocultural perspective [7].

Working within an engineering context, no students enter the program with a complete command of Professional Engineering language. Within engineering, ordinary words such as scope, stress, load or requirements take on new, discipline specific meanings. These meanings reference concepts and relationships that students are just beginning to develop. This language learning task comprises a major challenge for all first year students and yet multilingual students are assessed 
primarily on their lexicogrammatical accuracy. I have proposed the concepts of agility and efficacy to supplement the traditional measures of lexicogrammatical accuracy because meaning-making seems to be more critical to a student's ability to successfully participate in the engineering activities than accuracy alone. The construction and establishment of shared understandings facilitates an engineering student's ability to participate on a design or project team as well as to participate in engineering education programs and eventually the profession. If we assess more than accuracy, we may be able to construct a more complete picture of students' ability to communicate and inform our pedagogy. However, in order to do this, it is necessary to find out what meaning-making, agility and efficacy look like in practice. In this study I examine emergent meaningmaking practices by examining the discourse of languagein-use and discourse as text [8] of video-recorded team meetings in two first year engineering design courses.

\section{Meaning-making Framework}

Agility, efficacy and to some degree, accuracy serve this meaning-making process. Agility refers to having diverse discourse, pragmatic, linguistic and rhetorical resources as well as recognizing when to deploy them in various contexts. Efficacy refers to how well a student deploys the different resources; that is how well is the level of frustration in reaching shared understanding managed.

\section{Study Design, Participants and Analysis Methods}

\subsection{Study Design}

The study, a non-participatory observation in two first year engineering design course, was conducted from January to end of April 2014. This meaning-making and accuracy study is part of a collaboration with Patricia Sheridan and her work on teamwork effectiveness. Student teams in both courses respond to a design challenge in the real world. Teams are comprised of five to seven members in Course A and three to four members in Course B. Teams in Course A work together over the 12-week term to produce a design and three deliverables that articulate the team's definition of the problem, the design requirements and the specifications of their recommended design. Teams in Course B spend 6 weeks defining an engineering opportunity and the requirements and 6 weeks responding to a design request. Students are expected to produce a conceptual design that is presented in a public showcase at the end of term.
Teams from both courses face the task of making a phone call to a client or potential client in the first two weeks of the term. In Course A, students are given explicit, written instructions to produce a script that must be approved by an instructor before the phone call can be made. This task, one of several, is to be accomplished during the first team meeting in the second week of the course. This is the first time the team members meet one another and is the first time they see their client statement.

In Course B, students are asked to make contact with a community that interests them. The ultimate outcome is to get to know enough about the lived experience of the members of that community to judge if there are any opportunities that first-year engineering students might engage with that could improve or have a positive impact on community members' experience. Student teams are given an opportunity for a 'walk-about' during a tutorial time. This involves one instructor who walks the length of the corridor outside the tutorial room with a team member who presents the team's reasons for interest in the community and requests additional opportunities for contact. Students are actively discouraged from producing scripts.

Seven teams, three from Course $A$ and four from Course B, volunteered to participate in the study. Each team was video recorded three times, once at the beginning of the term, once near the mid-point of the term and once at the end of the term. All video recordings were made in a private room with three cameras positioned around the room to capture all team members and any shared workspaces such as a whiteboard or flip chart. Due to the classroom configuration of Course $\mathrm{B}$, recordings did not take place during tutorial times. Instead, recordings were made of meetings students scheduled outside of class times. All recordings were accomplished within the same time periods as those made in Course A. Individual team members also met the two researchers for a stimulated recall interview during the exam period after all deliverables had been submitted. Stimulated recall interviews were based on the selection of critical incidents. A critical incident was defined as an interaction where a shared understanding was established, a decision was made or the attempt was abandoned, or a contentious issue was raised. Three to five short (40 second to 90 second) clips were shown to students who were then asked to recall all details of the incidents including how they felt, how they think their interlocutors felt, their intentions and expectations of the incidents.

\subsection{Study Participants}

For this paper I have chosen to examine incidents from two teams [Table 1]. Team 1 is comprised of five males from different engineering disciplines. In spite of a 
promising beginning, the team did not work together effectively even though the individual team members appeared to freely express their ideas and perspectives.

Team 3 is comprised of three students from Course B. They characterized themselves as an effective team who shared responsibilities and shared a common goal. They freely disagreed with one another, critiquing each other's ideas throughout their meetings but nevertheless remained focused on producing a design that would be different from other teams working on the same design challenge.

Table 1: Team language and gender demographics

\begin{tabular}{|c|c|}
\hline \multicolumn{2}{|l|}{ Team 1 (Course A) } \\
\hline 1 Male (Ken) & English dominant \\
\hline 2 Males (Vincent, Zhao) & $\begin{array}{l}\text { Non-English dominant, } \\
\text { Chinese }\end{array}$ \\
\hline $\begin{array}{l}2 \text { Males (Hisham, } \\
\text { Mehrdad) }\end{array}$ & Non-English dominant, \\
\hline \multicolumn{2}{|l|}{ Team 3 (Course B) } \\
\hline 1 Male (Case) & $\begin{array}{l}\text { Cantonese, Mandarin, } \\
\text { English }\end{array}$ \\
\hline 1 Female (Allie) & $\begin{array}{l}\text { Cantonese, Mandarin, } \\
\text { English }\end{array}$ \\
\hline 1 Male (Greg) & Mandarin, English \\
\hline
\end{tabular}

\subsection{Analysis Methods}

Video recordings were viewed and coded using a constant comparative analysis [9]. Individual speech moves were coded as well as gestures. Meaning-making episodes were defined as some series of discourse moves that resulted in some kind of shared understanding. Agility appeared and was coded when some change in language, mode, perspective, or register in order to facilitate meaning-making occurred. Efficacy, or its absence, was noted when shared understanding was achieved or the attempt was abandoned.

A sociocultural perspective presumes complexity in meaning-making interactions Looking at the language alone was not enough to understand how the students made meaning. It was important to consider what resources or artifacts a student had in any given context and the student's interaction with those artifacts. These artifacts included the course text, lectures, assignment instructions as well as any previously completed assignments and feedback from them. It was also important to consider other interlocutors, such as course instructors and TAs, as part of the set of affordances and artifacts students worked with. The language used must also be considered in relation to the degree of shared understandings, knowledge and goals with other interlocutors (See Radford and Roth [10] for a more detailed discussion of the concept of togethering).

In order to accommodate this complexity a discourse analysis approach that focused on discourse as text and language-in-use was used. Discourse as text according to Bloome et al refers to "a social space in which people create meaning". Bloome et al continue to describe a printed text as an artifact of "the transformation by people of events, experiences, or any phenomenon into language" [8]. The experience of meeting a design challenge requires the transformation of experiences and understandings into language, in this case a very specific language of engineering and design. Teams from both courses produced written texts in the form of design specification documents, requests for proposals, presentation slides or posters. Language-in-use allows the inclusion of "all of the semiotic devices that might be used in a face-to-face interaction such as utterances, prosody, nonverbal actions, pictures, and the use of artifacts and objects" [8].

The following table shows coding categories that have emerged over the course of analysis. The categories reflect both verbal and non-verbal moves made during the interactions.

Table 2: Coding categories for Teams 1, and 3

\begin{tabular}{|c|c|c|}
\hline Nominates & Qualifies & $\begin{array}{c}\text { States personal } \\
\text { 'state' }\end{array}$ \\
\hline Reads & Confirms & Counters \\
\hline $\begin{array}{c}\text { Seeks } \\
\text { clarification }\end{array}$ & $\begin{array}{c}\text { Seeks } \\
\text { confirmation }\end{array}$ & Accepts \\
\hline $\begin{array}{c}\text { Affective } \\
\text { interjection }\end{array}$ & Corrects & Refocuses \\
\hline Affirms & Adds & $\begin{array}{c}\text { Seeks } \\
\text { interpretation }\end{array}$ \\
\hline $\begin{array}{c}\text { Seeks } \\
\text { information }\end{array}$ & $\begin{array}{c}\text { Offers } \\
\text { opinion }\end{array}$ & Ignores \\
\hline $\begin{array}{c}\text { Provides } \\
\text { information }\end{array}$ & $\begin{array}{c}\text { Changes } \\
\text { topic }\end{array}$ & Objects \\
\hline Agrees & Explains & Seeks definition \\
\hline Expands & Suggests & Provides definition \\
\hline Repeats & Justifies & $\begin{array}{c}\text { Reference to } \\
\text { course artifact }\end{array}$ \\
\hline $\begin{array}{c}\text { Offers } \\
\text { experience }\end{array}$ & $\begin{array}{c}\text { Assigns } \\
\text { task(s) }\end{array}$ & Stops discussion \\
\hline $\begin{array}{c}\text { Seeks } \\
\text { decision }\end{array}$ & Concludes & $\begin{array}{c}\text { Offers personal } \\
\text { experience }\end{array}$ \\
\hline Suggests & $\begin{array}{c}\text { Offers } \\
\text { evidence }\end{array}$ & Re-states \\
\hline
\end{tabular}

\section{Analysis}

For the purpose of this article excerpts from critical incidents that illustrate the relationship between lexicogrammatical accuracy and meaning-making or shared understanding and agility are presented. These represent trends in the analysis of the all three meetings of 
Table 3: Transcript excerpts with discourse moves and coding categories

\begin{tabular}{|c|c|c|}
\hline Move & Text & Codes \\
\hline Request & PM: Okay, let me sit here. Okay, ring, ring, Hello & Role-play \\
\hline Greeting & K: Uh, good afternoon, Miss Marie Rollings. My name is Ken Chivas. & \\
\hline Disrupt & PM: Mom, I think it's for you. & \\
\hline Prompt & H: (Sotovoce) And then the mom comes to you, say it again & Offers info \\
\hline $\begin{array}{l}\text { Accept, } \\
\text { Greeting }\end{array}$ & $\begin{array}{l}\text { K: Oh, right. Oh, good afternoon, Miss Marie Rollings, Good afternoon, Miss Marie Rollings (reads } \\
\text { from script }\end{array}$ & $\begin{array}{l}\text { Accept } \\
\text { info }\end{array}$ \\
\hline Greeting & K: Good afternoon? & Repeats \\
\hline Greeting & K: Good afternoon & Repeats \\
\hline Repeat, & PM: Mom, I think it's for you....what's going, what's going wrong here? & Seeks info \\
\hline Respond & H: It's a kid, it's a kid & $\begin{array}{l}\text { Provides } \\
\text { info }\end{array}$ \\
\hline Respond & V: It's a kid picking up the phone, right. & Confirms \\
\hline Suggest & $\mathrm{V}: \mathrm{Hi}$, how's it going & Suggests \\
\hline Guide & PM: So, what SHOULD you say? & $\begin{array}{l}\text { Seeks } \\
\text { response }\end{array}$ \\
\hline Suggest & V: Kid, could you & Suggest \\
\hline Prompt & PM: When you start out? & Expands \\
\hline Attempt & $\mathrm{K}$ : Uh, Hi, my name is Ken Chivas (reads from script) & Repeats \\
\hline Guide & H: Who, Whom am I speaking to & Suggests \\
\hline Support & PM: Okay, so far, so good and & Confirms \\
\hline Attempt & K: I'm calling on behalf of (reads from script) & Repeats \\
\hline Guide & PM: Who are you calling? Whom are you calling? & Repeats \\
\hline Respond & K: I'm calling Miss Marie Rollings (reads from script) & Repeats \\
\hline Guide & PM: But you don't know if she's answering the phone, so you should say.. & Clarify \\
\hline Attempt & K: Who am I speaking to & Suggest \\
\hline Attempt & H: Am I speaking to? & Re-phrase \\
\hline Approves & PM: Okay, May I speak to & $\begin{array}{l}\text { Provides } \\
\text { info }\end{array}$ \\
\hline Concludes & All: Ahhhhhh, ohhhhhhh, (laughter) & $\begin{array}{l}\text { Affective } \\
\text { interjection }\end{array}$ \\
\hline
\end{tabular}

\begin{tabular}{|c|c|c|}
\hline Move & Text & Codes \\
\hline & C: Hi, This is XXXX Community centre & Role-play \\
\hline Prompts & A: How... what can & Suggests \\
\hline Greeting & C: How can I help you? & $\begin{array}{l}\text { Accepts, } \\
\text { rephrase }\end{array}$ \\
\hline $\begin{array}{l}\text { Greeting } \\
\text { Request }\end{array}$ & G: Hello, my name is Greg and I'm a student at the university of Toronto. Do you have a moment? & Improv \\
\hline $\begin{array}{l}\text { Respond } \\
\text {, invite }\end{array}$ & C: Yes, I do, Please do stay & $\begin{array}{l}\text { V error, } \\
\text { improv }\end{array}$ \\
\hline $\begin{array}{l}\text { Explain, } \\
\text { add, } \\
\text { request }\end{array}$ & $\begin{array}{l}\text { G: I really appreciate all the things you have done and....help your members there and so I'm a team } \\
\text { of three right now working on an engineering project so we're currently trying to gather some } \\
\text { information of your community and we want to schedule an appointment with you sometime at the } \\
\text { beginning of next week. Is that possible? }\end{array}$ & $\begin{array}{l}\text { Syntax, } \\
\text { prep error, } \\
\text { improv }\end{array}$ \\
\hline $\begin{array}{l}\text { Request } \\
\text { info, } \\
\text { rephrase }\end{array}$ & $\begin{array}{l}\text { C: Uh, I was wondering what's your purpose of appointment, what you wan...t, what you, what } \\
\text { would you wish us to do? }\end{array}$ & $\begin{array}{l}\text { Pivot, } \\
\text { syntax, re- } \\
\text { phrase }\end{array}$ \\
\hline $\begin{array}{l}\text { Respond } \\
\text {, expand }\end{array}$ & $\begin{array}{l}\text { G: So, we just want to learn more about community and possibly find some issues you concern and } \\
\text { we will later frame it as engineering problem and can possibly be solved by, uh, um, by }\end{array}$ & $\begin{array}{l}\text { Improv, } \\
\text { v-form }\end{array}$ \\
\hline Prompt & A: uh,team of 3 & Suggests \\
\hline Expand, & $\begin{array}{l}\text { G: By our team or like other teams in our class (ahhh, sigh) or, or, or other teams that or other teams } \\
\text { or other people who have the same interests with us }\end{array}$ & $\begin{array}{l}\text { Re- } \\
\text { phrase, } \\
\text { improv }\end{array}$ \\
\hline Decline & C: I'm sorry, we have (begins to laugh) we don't, we don't have enough resources for you (laughter) & $\begin{array}{l}\text { Pivot, } \\
\text { improv }\end{array}$ \\
\hline \multirow[t]{2}{*}{ Close } & G: Okay, bye. & \\
\hline & Ahhh! & Affect \\
\hline Critique & C: It's too long & Switch \\
\hline Agree & G: Yeah, I know & Agree \\
\hline
\end{tabular}


Teams 1 from Course A, and Team 3 from Course B. Incidents for this article are taken from the first meetings of Teams 1 and 3.

\subsection{Team 1}

Approximately 45 minutes into their first meeting, Team 1 begins to write the telephone script to contact their client. This is the last part of an episode concerned with deciding how to address the client. This was preceded by a discussion of what title they should use (Dr., Miss, Mrs.) Ken (All names are pseudonyms to maintain participant anonymity.), who has been nominated and agreed to be the caller, states that he doesn't want to use the client's first name. Victor proposes an alternative and suggests that it is variable, depending on the time of day, but that the decision can be made by the caller. Ken claims the decision to be based on his "sense" and Victor agrees. Victor, referring to the instructions proposes the next move in the call, "We have to identify ourselves." Hisham refers to the written instructions he has displayed on his laptop and labels the move as part of the "Greetings." He appears to start a question which Victor takes up and queries if another move needs to be made. He is talking about the accepted discourse moves in a phone call in Canada - can you move directly from "Hello" to identifying yourself or does there need to be something else, a politeness move. Victor proposes two alternatives, in jest, but Hisham appears to take the suggestion seriously and evaluates them as, "That's bad." He begins to propose an alternative but Ken cuts him off and ends this part of the discussion.

Team 1 spends much of the next 40 minutes wordsmithing their call. They are gathered around a flip chart stand that has been placed on the table. Ken records as they compose together. The Project Manager (PM) enters the room an hour and twenty-five minutes after they began their meeting, saying, "Let's have a shot at this. Ring, ring, ring." Ken begins reading from their script but the PM mimes holding his hand over the receiver and shouting, "Mom, I think it's for you." Ken stops. He starts again from the script and the PM repeats, "Mom, I think it's for you." This happens once more before the PM interrupts with, "What's going wrong here. What should you say?" In the end, the PM feeds Ken the line, "May I speak to..." which fills in the politeness move that Victor had queried much earlier in the scripting process.

\subsection{Team 3}

This episode begins about 10 minutes into the meeting the day after the tutorial during which the 'walk-about' occurred. Case begins by going through the tasks he thinks they need to accomplish. Allie agrees, Case accepts this and then Allie adds the information that Greg had done the walk about the day before. Case requests information, an evaluation of the experience and asks 'to see'. Greg responds literally to the question, Case laughs, apparently understanding that it is not a literal request, $\mathrm{He}$ offers an alternative, although he uses the same phrase, "Can I see" but with a different inflection. Greg continues to refuse because there is no recording when Case clarifies, this time explicitly stating, "I want to talk". Allie directs Case to 'talk to him (Greg)' which Case takes up and expands with a request for information about what community he wants him to pretend to represent. Greg indicates his understanding and willingness to engage in this activity with "You're..." and names the community and Case's role as the front desk receptionist. Case agrees and then switches into the role, holding his phone to his ear and begins using a 'telephone voice.' Greg responds and improvises an explanation of why he is calling. Over the next few minutes they abandon the role play proper but continue to try out a variety of ways of representing who they are, requesting information and requesting time. Each suggestion is critiqued and compared with advice Greg and Allie had gleaned from their instructor during the 'walk-about'. In an incident approximately 20 minutes later, the team returns to role-playing phone calls using information on various potential communities they had researched. They spend approximately 50 minutes roleplaying different phone calls, each taking turns playing both the role of the caller and the receiver and generating several different scenarios to use. The team moves fluidly between the role play and critique, "That's too long!".

\section{Discussion}

Team 1 (Table 3 ) is constrained by several things in their ability to successfully build meaning and shared understanding. Although the team commits to a shared goal, completing the phone script, they rely on the artifact of the instructions to guide what they produce. They interpret the instructions at a literal level rather than trying to understand and act on the higher level objectives of the instructions, "setting up a meeting between the entire team and the client." All team members remained fixated on grammatical accuracy, the content and a level of professional formality as prescribed in the instructions. Their intention was to produce a script that could be approved by their PM. Their meaning-making is confined to micro-level decisions about titles or request syntax that will fulfill that intention. The narrow focus on completing a script and rigidity of their wordsmithing efforts denied them permission to deviate from their interpretation of the goal. The language used is lexicogrammatically accurate with only minor syntax or subject-verb agreement errors 
in the oral discussion. They exhibit no agility in approaching the phone call as a communication task resulting in the 'failure' of their role play with the PM. They have been so focused on crafting a message that they neglected the challenge of making meaning through the act of a telephone call.

Team 3, (Table 4) on the other hand, exhibits a number of lexicogrammatical errors (subject-verb agreement, tense, pronoun use, vocabulary choices, pronunciation) and considerable agility. The errors do not impede the establishment of a shared goal, planning how to approach potential clients for an engineering design project. The instructions they have been given focus on establishing a rapport that will help the team gain access to a community they are interested in getting to know. The team interprets the instructions in terms of practicing how they will approach and establish rapport with potential clients. As a result they are focused on generating possible scenarios and responses by putting themselves into a situation where they need to respond to unexpected utterances e.g. "what would you expect us to do? We don't have enough resources." They switch perspectives and roles fluidly, moving from role-play to critique to revision between and sometimes even within turns. The number of lexicogrammatical errors in their role-played phone calls had considerably reduced by the end of their meeting. They had accurately incorporated a number of lexical chunks gleaned from each other and from previous feedback making their final role-plays more linguistically and pragmatically accurate.

\section{Implications}

These two short excerpts begin to show the complexity of assessing students' communication skills. On one level the script produced by Team 1 would indicate a degree of competency in carrying out a specific communication activity. The transcript of Team 3's efforts, if based on accuracy of syntax, usage and pronunciation would most likely indicate a group with limited competency. However, if an observer/assessor takes into consideration the entire interaction including reference to and use of artifacts, ability to make meaning in response to an unanticipated cue, Team 3 exhibits more competency.

Given the complexity of meaning-making, it is clear that lexicogrammatical accuracy is only one element of the meaning-making phenomenon yet it has been given the responsibility of serving as a proxy for language proficiency, content understanding and ability to productively participate. Much of engineering learning and engineering work is carried out in teams in the verbal back and forth that asserts, challenges, and builds ideas. This is the discourse-as-text Bloom et al [8] refer to that transforms these team meetings into an understanding and control of engineering concepts, professional engineering language and practices and, finally on a very concrete level, documents, posters and presentations. A basic tenet of this is that a team, a pair or whatever size group is able to make and share meanings in order to successfully make this transformation.

The present reliance on lexicogrammatical accuracy seems to be an impoverished construct on which to assess students' understanding and students' ability to productively interact and use the concepts and tools of the profession in a team setting. Our assessment practices require revision in terms of what is assessed, how it is assessed and where it is assessed. While certainly maintaining the category of lexicogrammatical accuracy, we need to add observation of agility and efficacy in the process of meaning-making. However, assessment is only part of the process in the support of professional language development for our students. The act of assessment needs to be coordinated and considered with the quality of the interactions with interlocutors and the artifacts of a course or assignment and the tools (whiteboards, flip charts and markers, electronic devices, etc.) available. Such a perspective requires the observation of teams-inaction and a close observation of their meaning-making processes. Agility could become one category of observable behavior in determining student effectiveness in communicating that supplements lexicogrammatical accuracy.

\section{Acknowledgements}

The author wishes to thank Patricia Sheridan, Jason Bazylak, Peter Weiss, Jason Foster and Rob Irish for their support of this research.

\section{References}

[1] ABET, 2012.

[2] L. Brooks and M. Swain, "Contextualizing performances: Comparing performances during TOEFL iBT $^{\text {TM }}$ and real-life academic speaking activities," Language Assessment Quarterly, vol. 11, pp. 353-373, 2014.

[3] A. Ginther, X. Yan, and J. Potts, "The relationship between TOEFL and GPA: The case of Chinese students," in Language Testing Research Colloquium, Toronto, ON, 2015.

[4] C. J. Hall, "Moving beyond accuracy: from tests of English to tests of 'Englishing"," ELT Journal, vol. 68, pp. 376-385, 2014.

[5] J. P. Lantolf, "Dynamic assessment: the dialectic integration of instruction and assessment," Language Teaching, vol. 42, pp. 355-368, 2009.

[6] J. P. Lantolf and M. E. Poehner, Sociocultural theory and the pedagogical imperative in L2 education: Vygotskian praxis and the research/practice divide. New York: Routledge, 2014. 
[7] L. S. Vygotsky, Thought and language. Cambridge, MA: The MIT Press, 1934/1986.

[8] D. Bloome, S. P. Carter, and B. M. Christian, On discourse analysis in classrooms: Approaches to language and literacy research. New York, NY: Economic Policy Insitute and Teachers College, 2008.

[9] B. G. Glaser and A. L. Strauss, The Discovery of Grounded Theory: Strategies for Qualitative Research. Chicago: Aldine Publishing Company, 1967.

[10] L. Radford and W. M. Roth, "Intercorporeality and ethical commitment: An activity perspective on classroom interaction," Educational Studies in Mathematics, vol. 77, pp. 227-245, // 2011. 